\title{
Characterization of piezoelectric films of foamed polyethylene obtained by extrusion
}

\author{
Halina Kaczmarek $^{1} \cdot$ Ewa Klimiec $^{2} \cdot$ Bogusław Królikowski $^{3} \cdot$ Marta Chylińska $^{1} \cdot$ \\ Monika Machnik ${ }^{2}$
}

Received: 21 April 2017 / Accepted: 19 July 2017 / Published online: 24 July 2017

(c) The Author(s) 2017. This article is an open access publication

\begin{abstract}
Foamed polyethylene (MDPE) films obtained by extrusion have been characterized by X-ray diffraction, thermogravimetric analysis and tensile tests. The piezoelectric properties have been determined by calculation of piezoelectric constant $\mathrm{d}_{33}$, thermally stimulated depolarized current method and calculation of activation energy depolarization of electrets. It has been found that the crystallinity and internal morphology, including cellular structure, affect the possibility of an effective polarization in order to obtain a piezoelectric material from foamed MDPE. The conditions of processing have a great influence on the piezoelectric properties. The value of piezoelectric constant attains $\sim 18 \mathrm{pC} / \mathrm{N}$ and $\sim 75 \mathrm{pC} / \mathrm{N}$ for low stress range and diminishes for higher stresses, temperature $\mathrm{T}_{\mathrm{m}} \sim 72{ }^{\circ} \mathrm{C}$ and $\sim 82{ }^{\circ} \mathrm{C}$, approximate activation energy attains 2.67 and $3.28 \mathrm{eV}$, for compacted and non-compacted film, respectively. Because of the simple and cheap method of foaming PE films of piezoelectric properties it is worthy to take care regarding their application for pressure sensors.
\end{abstract}

Halina Kaczmarek

halina@umk.pl

1 Faculty of Chemistry, Nicolaus Copernicus University in Toruń, Gagarina St. 7, 87-100 Toruń, Poland

2 Institute of Electron Technology - Kraków Division, Zabłocie St. 39, 30-701 Kraków, Poland

3 Institute for Engineering of Polymer Materials and Dyes Toruń Division, M. Skłodowskiej-Curie St. 5, 87-100 Toruń, Poland

\section{Introduction}

Polyolefins have enjoyed for many years of sustained popularity thanks to a well-known technology of manufacturing, not high cost of production and the possibilities of structure modification leading to new beneficial properties [1,2]. A large progress has been recently observed in the manufacturing of polyolefins (polyethylene-PE, polypropylenePP and their derivatives) having a strictly planned, welldefined structure of macromolecules by using metathesis and specifically designed catalysts [2-5]. It is not without significance the polyolefin waste utilization in the recycling process [6]. Moreover, it is possible to obtain functionalized macromolecules of PE and PP, which contributes to the change of their properties and significantly expands the use in numerous industrial sectors. For example, the hydrophobic nature of the polyolefins may be modified by introducing of the polar groups to macromolecules in the process of copolymerization, which changes the surface properties, adhesion to various substances, printability and miscibility with other plastic components or polymers $[3,7,8]$. Of great significance in the planning of specific applications (medical, biotechnological, etc.) of polyolefins has a precise control of chemical structure and morphology, which is possible due to sophisticated, complementary instrumental techniques.

In common applications, dielectric properties of polyolefins are important and often used. These features are also necessary for obtaining piezoelectric materials.

The requirement for obtaining piezoelectric properties of electro-active polymers is their durable polarization. For polar materials such as poly (vinylidene fluoride), this is a lasting arrangement of molecular dipoles. In the case of non-polar materials such as polypropylene or polyethylene, it is a permanent arrangement of the charges 
resulting from the structural defects of the material as well as the charge introduced into the material during the polarization process under the influence of strong electric field. The structural defects in polyolefins can be the residues of initiators or catalysts from the polymerization, incorporated into the macromolecules.

Permanently polarized materials exhibit an external electric field, and by analogy to magnets they are called electrets.

Recently, there appear reports on such materials based on polyolefin, which can be used for manufacturing of sensors and strain gauge for biomedical applications [9-11]. Particular attention was paid to research of semicrystalline polypropylene. It proved that the PP doped with inorganic substances forms stable electrets [12-16] due to the ordered polymer structure and some particular defects-the inner cavities (cells) filled with air or dopants of other substances. The detailed mechanism of trapping charges in polymer matrices is still under discussion. Generally speaking, it is believed that for the storage charge are responsible physical and/or chemical traps which may include impurities, structural disorders or free radicals captured in the polymer network.

New piezoelectrics based on polymers are still sought because of their valuable physicochemical properties (e.g. flexibility, durability, low density) and the possibility of forming any shapes and sizes of products in conventional molding processes. It has been repeatedly confirmed that good piezoelectric properties have semicrystalline polymers with a cellular structure [14, 17-20]. On the basis of reviewing the current literature shows that an isotactic polypropylene is already recognized as a potential piezoelectric material (besides of PVDF or PFTE) [12-16], however, other polyolefins, including polyethylene, are still not well investigated. In practice, there is no problem with obtaining cellular structure in $\mathrm{PE}$, for example, through the corona discharge or use the foaming compound. Moreover, the degree of crystallization in PE film can be enhanced by orientation process or addition of nucleating agent.

In view of the scientific reports on the beneficial effect of cellular structure in the polymer on the piezoelectric properties, we decided to study whether the foamed polyethylene creates a structure providing formation of electrets. Thus, the aim of this study was to obtain and characterize properties (including piezoelectricity) of films prepared from medium density polyethylene (MDPE) containing chemical blowing agent. In this work few instrumental techniques have been used to determine the relationship between structure and properties of chosen MDPE. According to our knowledge it is the first study of foamed polyethylene from the viewpoint of its potential piezoelectric properties and application in sensors technology.

\section{Experimental part}

\subsection{Materials}

A commercial medium density polyethylene (MDPE) containing blowing agent (Borcell ${ }^{\mathrm{TM}}$ ME 1244, Borealis AG) has been used. Purchased polymer is present in the form of a slightly yellow granules. The polymer films of $145 \mathrm{~mm}$ width and different thickness $(100-200 \mu \mathrm{m})$ have been obtained by extrusion using single-screw lab extruder Plasti-Corder PLV 151 Brabender in the following conditions: extruder heating zones-225, $235,235{ }^{\circ} \mathrm{C}$, temperature of extrusion die head $-245{ }^{\circ} \mathrm{C}$, screw speed $-75 \mathrm{~s}^{-1}$. For thinner films, extruded samples were subjected to further compression in a hydraulic press (Graseby Specac, $9 \mathrm{~cm}$ diameter mold) at a temperature of $140{ }^{\circ} \mathrm{C}$ in time of $0.5 \mathrm{~min}$ with a load of approximately 2 tons.

\subsection{Characterization}

The morphology of received MDPE films has been observed by scanning electron microscope LEO 1430 working in controlled vacuum.

Crystallinity of samples have been studied by X-ray diffraction X'PERT Pro Philips Diffractometer using $\mathrm{Cu} K_{\alpha} 1$ radiation (wavelength $1.54056 \AA$ ), range $2 \theta 5^{\circ}-90^{\circ}$, scan step size $0.020^{\circ}$ and time per step $3.00 \mathrm{~s}$. The method of determining the degree of crystallinity described in detail previously [16].

Thermogravimetric analysis was carried out using simultaneous thermal analyzer NETZSCH STA 449 F5 Jupiter $^{\circledR}$ (NETZSCH-Gerätebau $\mathrm{GmbH}$ ) in nitrogen atmosphere. This apparatus enables to record TG, DTG and DSC curves in one measurement. The heating rate and the gas flow rate were $10{ }^{\circ} \mathrm{C} \mathrm{min}^{-1}$ and $100 \mathrm{~mL} \mathrm{~min}{ }^{-1}$, respectively. Proteus Thermal Analysis (Version 6.1.0) software has been used for results elaboration and presentation.

ATR-FTIR spectra have been obtained using Vertex 70v with RT-DLaTGS Wide Range detector and ATR device (Bruker Optics Gmbh, Ettlingen, Germany), with diamond crystal (in the vacuum below $100 \mathrm{~Pa}$ ).

Raman measurements were performed at room temperature using confocal microRaman spectrometer (Senterra Raman microscope R200-L with laser safety enclosure, Bruker Optics Gmbh, Ettlingen, Germany) with a high resolution of $9 \mathrm{~cm}^{-1}$ and $\lambda_{\mathrm{exc}}=785 \mathrm{~nm}$ diode laser excitation in $400-3600 \mathrm{~cm}^{-1}$ region.

The study of the mechanical properties was performed using a tensile testing apparatus TIRAtest 27,025 equipped with a $3 \mathrm{kN}$ head at room temperature. The feed speed of crosshead was $\mathrm{V}_{1}=1.0 \mathrm{~mm} \min ^{-1}$ (in the initial stage of the tensile, to $2 \%$ elongation) and $\mathrm{V}_{2}=100.0 \mathrm{~mm} \mathrm{~min}^{-1}$ (from $2 \%$ elongation to break). Dimensions of the samples 
were $50 \mathrm{~mm} \times 15 \mathrm{~mm}$. Obtained results are the average of at least ten measurements.

Piezoelectric properties of foamed MDPE films were tested on extruded films and films additionally compressed at $140{ }^{\circ} \mathrm{C}$. To manufacture the electrets, the films were polarized at constant electric field $100 \mathrm{~V} \mathrm{\mu m}^{-1}$, in a climatic chamber (VMT Heraeus-Vötsch). The samples were placed between two metal contact electrodes and then heated up to $85{ }^{\circ} \mathrm{C}$. After reaching the upper temperature the voltage was switched on, and voltage value gradually increased. The polarization time was $1 \mathrm{~h}$. The sample was then cooled down to room temperature and the voltage as switched off. The electric field and the temperature were selected for film basing on its breakdown voltage $>100 \mathrm{~V} \mu \mathrm{m}^{-1}$ at $85^{\circ} \mathrm{C}$. The density of the piezoelectric charge is proportional to stress and the piezoelectric constant $d_{33}$ is the coefficient of proportionality, whose value was calculated from dependence:

$\mathrm{q}=\mathrm{d}_{33} \times \mathrm{P}$

where q density of the piezoelectric charge, $P$ stress, $d_{33}$ piezoelectric constant.

The stability of the electrets stored at room temperature has been systematically examined. The voltage and charge have been measured every few days (up to 38 or 82 days). Electrets durability was tested by the thermally stimulated depolarization current (TDSC) technique in the temperature range from room temperature to $120^{\circ} \mathrm{C}$. The activation energy for the depolarization process was calculated by taking the natural logarithm of Arrhenius' equation:

$\ln (I(T))=$ const $-\frac{E}{k T}$

where $\mathrm{I}$ is the current density, $\mathrm{E}$ is the activation energy, $\mathrm{k}$ is the Boltzmann constant and $\mathrm{T}$ is temperature in Kelvins.

Therefore, a plot of $\ln (\mathrm{I})$ versus $1 / \mathrm{T}$ gives a straight line, whose gradient can be used to determine activation energy E. This relationship is used in initial-rise method [21].

\section{Results and discussions}

\subsection{Scanning electron microscopy (SEM)}

The morphology of the film surface obtained by extrusion method varies depending on the side of the sample. The surface of the film that had direct contact with hot rollers, is smooth and glossy, while the opposite side is more matte and rough. SEM images of both sides of the film show further differences in the structure of the surface (Fig. 1). As can be seen in Fig. 1a, structure observed in microscale is typical for polymer obtained by rapid cooling of melt. The second side of film shows the chaotically scattered lamellar structures in the polymer (Fig. 1b). However, in the same specimen elongated lamellar layers arranged in the plate are seen after higher magnification (such layout included in the Fig. 1c in brackets).

The cross-section of MDPE films shows cellular structure. Interestingly, this porous structure does not disappear after compression molding at $140{ }^{\circ} \mathrm{C}$ (Fig. 1d). On the basis of cross-sectional images of samples taken at various magnifications estimated cavity size in the range of $0.01-0.08 \mu \mathrm{m}$.

\subsection{X-ray diffraction}

X-ray diffraction pattern of the foamed polyethylene (Fig. 2) exhibits two main reflections in studied range at $2 \Theta: 21.4^{\circ}$ and $23.7^{\circ}$, corresponding to the orthorhombic unit cell structure of (110) and (200) planes in PE crystallites, which is consistent with literature reports [22, 23]. The last small signal at $2 \Theta=29.1^{\circ}$ can be attributed to the residues of the foaming agent. This is very probable because it decreases after processing and almost completely disappears after additional compression molding of sample at $140{ }^{\circ} \mathrm{C}$.

To quantitatively estimate the degree of crystallinity (X, \%) of MDPE, the recorded XRD curve has been deconvoluted for components assigned to the crystalline and amorphous phases using Voigt function, for which the best curve fitting has been achieved. The background has been described by a linear function. In diffraction angle range of $10-30^{\circ}$, the fraction of the integral intensity of the sharp peaks gives the degree of crystallinity similar to that determined by other experimental methods. The peak at $2 \Theta=29.1^{\circ}$ was not taken into account when calculating the degree of crystallinity of the polymer (its surface area was subtracted from the total area under the XRD curve). The result of XRD mathematical distribution is presented in Fig. 2.

The data listed in Table 1 shows that the degree of crystallinity slightly increases from 62.1 to $63.9 \%$ after molding at $140{ }^{\circ} \mathrm{C}$ although it was short-term heating (only $30 \mathrm{~s}$ ). At the same time, on the basis of almost identical values of half-widths (FWHM) of signals at $21.4^{\circ}$ and $23.7^{\circ}$ it can be stated that crystallite size did not change at this time.

\subsubsection{Thermogravimetric analysis}

The thermal stability of extruded and additionally heated MDPE has been investigated by thermogravimetric analysis (TGA). Figure 3 shows TG, DTG and DSC curves for extruded MDPE. The main parameters determined from TGA for both type of samples (extruded and compacted) are collected in Table 2. 
Fig. 1 SEM images of blown, extruded MDPE film: surface of gloss side (a), surface of mat side (b), details on mat side surface-yellow brackets indicate an ordered lamellar layer (c), cross-section of MDPE film after additional compacting at $140{ }^{\circ} \mathrm{C}(\mathbf{d})$. (Color figure online)
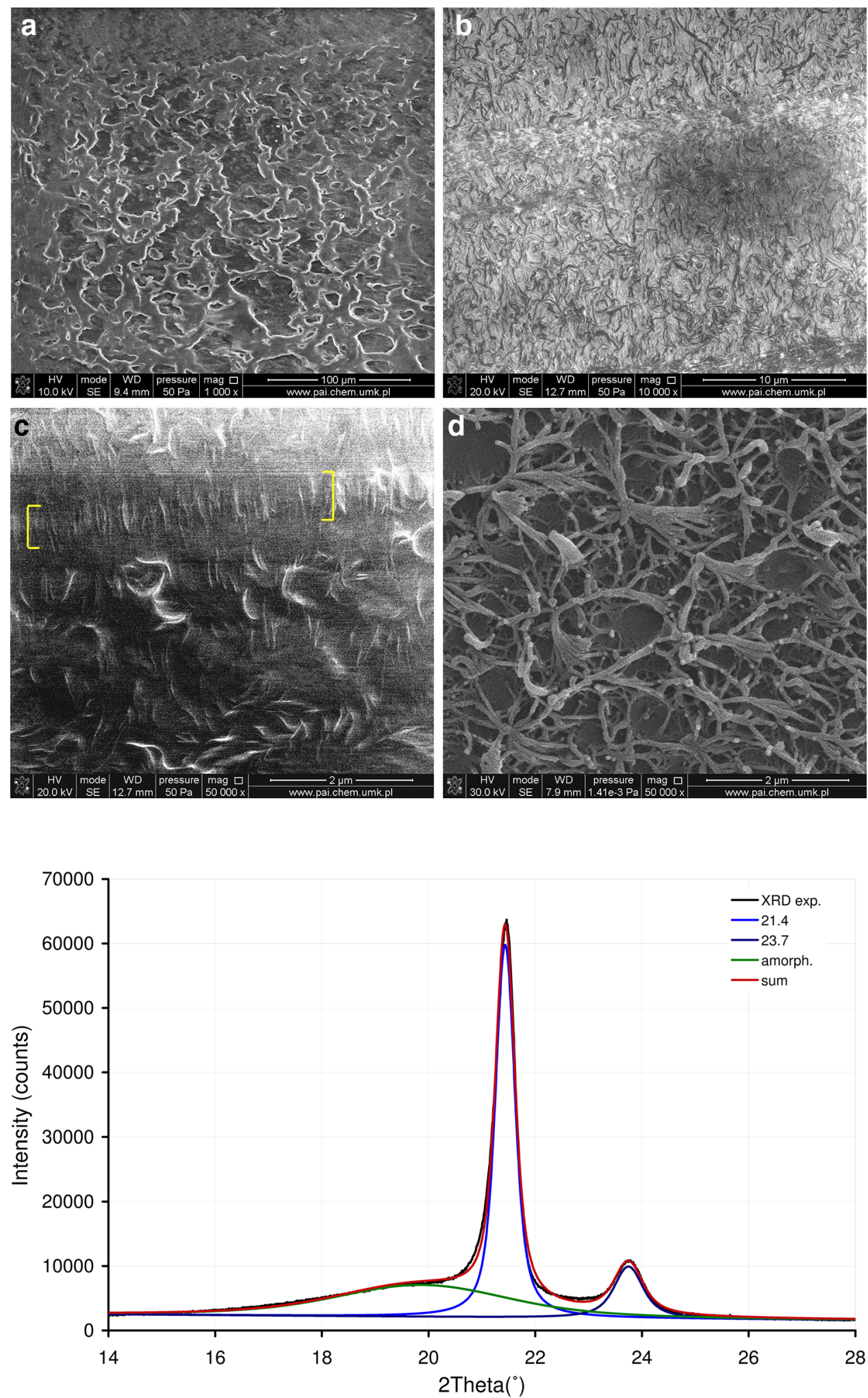

Theta(
Fig. 2 XRD patterns of blown MDPE and curve fitting of experimental XRD data showing individual componet signals
The studied polyethylene undergoes the single-stage thermal decomposition, which starts above $450{ }^{\circ} \mathrm{C}$ and ends about $500{ }^{\circ} \mathrm{C}$. Decomposition is almost completecarbonaceous residue at $600{ }^{\circ} \mathrm{C}$ is no more than $2 \%$.
As is known from the literature, the main products secreting during thermal decomposition of $\mathrm{PE}$ are saturated or unsaturated hydrocarbons containing different number of carbon atoms [24-26]. This is the result of random chain 
Table 1 Main signals at $2 \Theta$ range of $10-30^{\circ}$ and their percentage contribution in the total surface area under the XRD curve, full-width at halfmaximum $\left(\mathrm{FWHM},{ }^{\circ}\right)$, as well as crystallinity degree of sample $(\mathrm{X}, \%)$ calculated after deconvolution of XRD curves

\begin{tabular}{|c|c|c|c|c|c|c|c|c|}
\hline \multirow[t]{2}{*}{ Sample } & \multirow{2}{*}{$\begin{array}{l}\text { Amorphous halo } \\
\text { share, } \%\end{array}$} & \multicolumn{6}{|c|}{ Position $\left(2 \Theta,{ }^{\circ}\right), \mathrm{FWHM}\left({ }^{\circ}\right)$ and share $(\%)$ of crystalline signals } & \multirow[t]{2}{*}{$\mathrm{X}, \%$} \\
\hline & & $2 \Theta$ & FWHM & $\%$ & $2 \Theta$ & FWHM & $\%$ & \\
\hline Borcell extruded & 37.9 & 21.4 & 0.43 & 51.1 & 23.7 & 0.58 & 11.0 & 62.1 \\
\hline Borcell compacted & 36.1 & & 0.45 & 49.5 & & 0.57 & 14.4 & 63.9 \\
\hline
\end{tabular}

Fig. 3 Thermogravimetric analysis of foamed, extruded MDPE

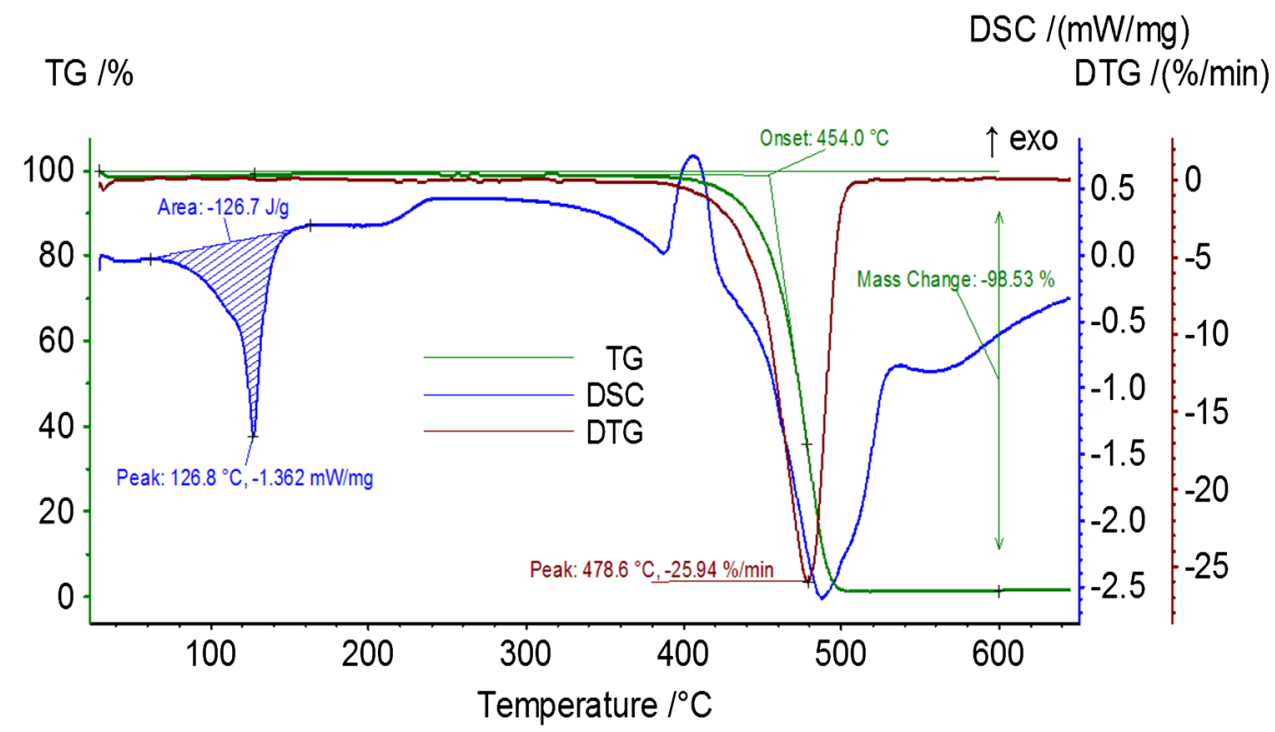

\begin{tabular}{lccccccc}
\hline Sample & $\mathrm{T}_{\mathrm{m}},{ }^{\circ} \mathrm{C}$ & $\Delta \mathrm{H}_{\mathrm{m}}, \mathrm{J} / \mathrm{g}$ & $\mathrm{T}_{\mathrm{o}},{ }^{\circ} \mathrm{C}$ & $\mathrm{T}_{\max },{ }^{\circ} \mathrm{C}$ & $\mathrm{T}_{\text {end }},{ }^{\circ} \mathrm{C}$ & $\Delta \mathrm{m}, \%$ & $\begin{array}{l}\text { Resi- } \\
\text { due at } \\
600{ }^{\circ} \mathrm{C}\end{array}$ \\
\hline Borcell extruded & 126.8 & 126.7 & 454.0 & 478.6 & 491.4 & 98.53 & 1.47 \\
Borcell compacted & 130.5 & 292.9 & 459.7 & 477.9 & 492.7 & 98.44 & 1.64 \\
\hline
\end{tabular}

Table 2 Main parameters determined from thermogravimetric analysis of foamed MDPE (extruded and additionally heated)

\subsection{ATR-FTIR and Raman spectroscopy}

scission of PE chains to shorter hydrocarbons. It was also found the evolution of significant amounts of hydrogen and the creation of nanocarbon structures (e.g. graphite-like) during PE thermal degradation in the inert gas atmosphere [26].

In the temperature range of $100-150{ }^{\circ} \mathrm{C}$, on the DSC curve appears an endothermic melting peak (Fig. 3b). The heat of fusion $\left(\Delta \mathrm{H}_{\mathrm{m}}\right)$ of the crystalline phase is $126.7 \mathrm{~J} \mathrm{~g}^{-1}$ for extruded sample. Unexpectedly, the $\Delta \mathrm{H}_{\mathrm{m}}$ value increases more than twice after the sample heating, although the change in crystallinity, determined by XRD, was small.

It is interesting that at approximately $410{ }^{\circ} \mathrm{C}$ an extra small exothermic peak appears in extruded sample, which almost disappears in the compacted film. The origin of this peak is not clear, maybe it is caused by a reaction of residues, which remained after decay of the blowing agent.
FTIR and Raman spectroscopies provide information about the chemical structure of polyethylene. As shown in Fig. 4, in FTIR spectrum, the absorption band characteristic for groups $\mathrm{CH} / \mathrm{CH}_{2} / \mathrm{CH}_{3}$ are present both in the stretching $\left(2915,2847 \mathrm{~cm}^{-1}\right)$ and the bending $(1472,1462,730$, $719 \mathrm{~cm}^{-1}$ ) vibration range [27]. There was no branching, vinyl groups or other functional groups which could indicate the presence of impurities. Moreover, the spectra do not show any chemical changes during sample extrusion and heating, which proves that processing does not cause chemical modification of macromolecule structure. Similarly, the Raman spectra of PE do not point to any structural differences or changes in the crystallinity of the samples. The bands at 1418 and $1169 \mathrm{~cm}^{-1}\left(\mathrm{CH}_{2}\right.$ bending and rocking, respectively) are attributed to the crystalline phase, 
Fig. 4 ATR-FTIR $(a)$ and Raman $(b)$ spectra of MDPE extruded film (the vertical axis for the FTIR spectrum corresponds to the transmission (\%), and for the Raman spectra- to the intensity of radiation)

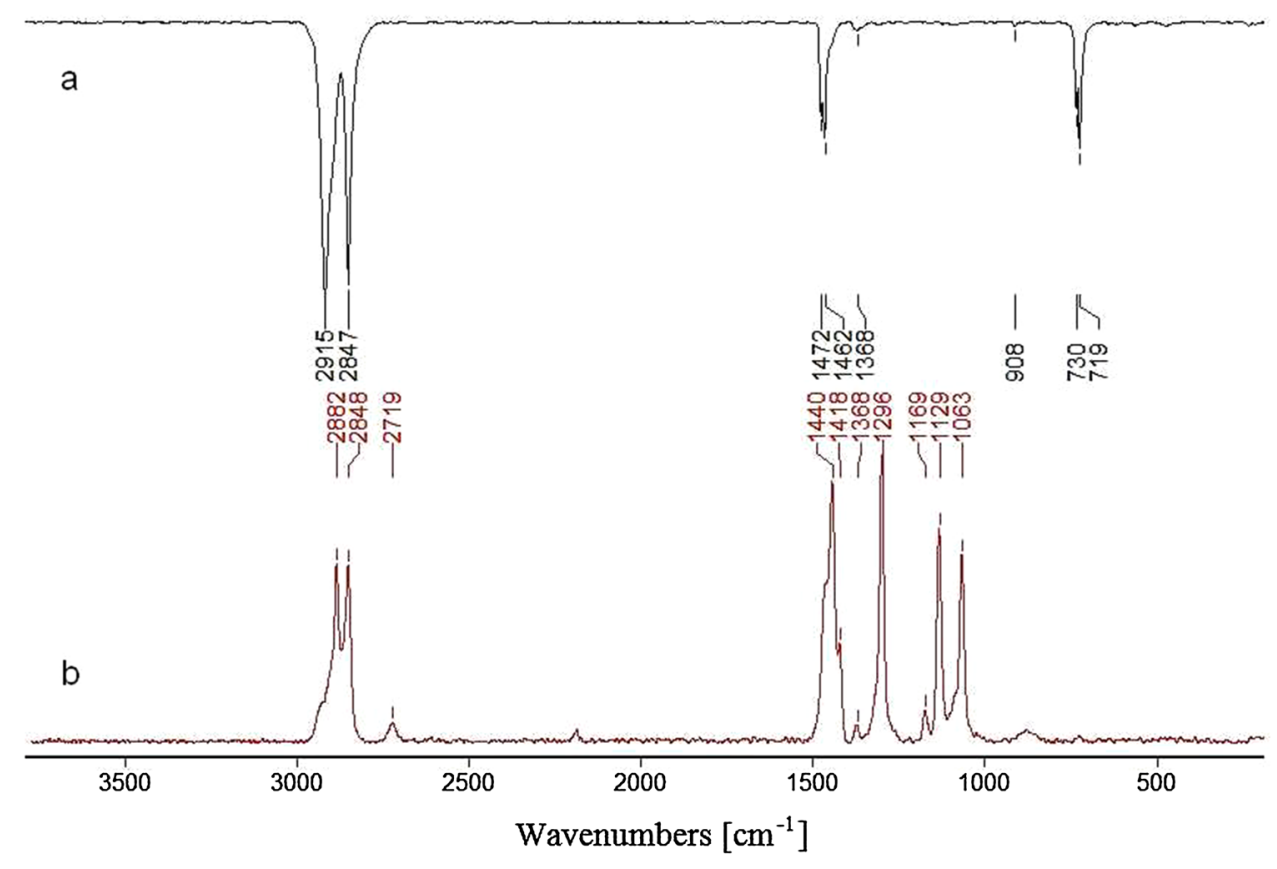

Table 3 Mechanical parameters for extruded, foamed MDPE film

\begin{tabular}{lllll}
\hline$\sigma_{\mathrm{m},}, \mathrm{MPa}$ & $\sigma_{\mathrm{b}}, \mathrm{MPa}$ & $\varepsilon_{\mathrm{m}}, \%$ & $\varepsilon_{\mathrm{b}}, \%$ & $\mathrm{E}_{\mathrm{t}}, \mathrm{MPa}$ \\
\hline 15.4 & 14.6 & 878 & 888 & 364 \\
\hline
\end{tabular}

whereas, bands at 1368 and $1063 \mathrm{~cm}^{-1}\left(\mathrm{CH}_{2}\right.$ wagging and $\mathrm{C}-\mathrm{C}$ stretching) to amorphous phase of PE. On the basis of the obtained spectra one cannot identify the presence of residue of blowing agent either because of its low content in the sample or the decomposition during extrusion/compacting process.

\subsection{Mechanical properties}

The mechanical parameters, strictly speaking tensile stress at break- $\sigma_{\mathrm{b}}$; maximum stress $-\sigma_{\mathrm{m}}$; elongation at break$\varepsilon_{\mathrm{b}}$; elongation at maximum stress- $-\varepsilon_{\mathrm{m}}$ and Young's modulus $-\mathrm{E}_{\mathrm{t}}$, determined from standard tensile test are presented in Table 3. It should be added, that $\mathrm{E}_{\mathrm{t}}$ has been determined from the straight line range of stress-strain relationship at the low stretching rate $\left(\mathrm{V}_{1}=1.0 \mathrm{~mm} \mathrm{~min}{ }^{-1}\right)$. The values of $\sigma_{\mathrm{b}}$ and $\varepsilon_{\mathrm{b}}$ determined in this work are even somewhat higher than those given by Borcell ME 1244 manufacturer, which according to the technical data sheet are $11 \mathrm{MPa}$ and $500 \%$, respectively [28]. This may be a result from a different method of preparation of samples for testing and other measurement conditions.

It should be added that the mechanical properties of the samples subjected to additional pressing using a laboratory press were not investigated because of the too small size of the obtained films. However, it can be assumed that the change in the initial stretching range should not be significant.

\subsection{Piezoelectric properties}

The measurements of piezoelectric charge and voltage at pressure $100 \mathrm{kPa}$ were carried out using electrets made of extruded and compacted films of thickness $\sim 120 \mu \mathrm{m}$ and $\sim 80 \mu \mathrm{m}$, respectively.

In the research the contact electrodes of surface $10 \mathrm{~cm}^{2}$ were applied. Dependence voltage-charge as a function of storing time at room temperature shows Fig. 5.

The TDSC tests were made on the same samples (Fig. 6) and an approximate activation energy of electrets depolarization processes was determined. As we can see from Fig. 6, the maximum of the current density for depolarization $\left(\mathrm{T}_{\mathrm{m}}\right)$ corresponds to 72 and $78{ }^{\circ} \mathrm{C}$ in extruded and compacted MDPE films, respectively.

Initial rise method results $[29,30]$ is accurate when considering the small fraction of the peak where the current density starts to increase. On the other hand, the current density in this temperature range is often related to a small signal-to-noise ratio or the occurrence of overlapping processes. In the case of the current density graphs of the tested materials, the first shows the presence of a process of a different nature in the initial phase of peak growth. For this reason, it was decided to set the temperature of the peak rise TL to 5 and $0 \%$ of peak height on its left side of curve obtained for extruded and compacted sample, 
Fig. 5 Dependence voltagecharge versus storing time at room temperature, 1 - extruded samples, 2-samples compacted at $140{ }^{\circ} \mathrm{C}$
Fig. 6 Courses of TSDC currents for samples: 1 - extruded, 2 - compacted at $140{ }^{\circ} \mathrm{C}$
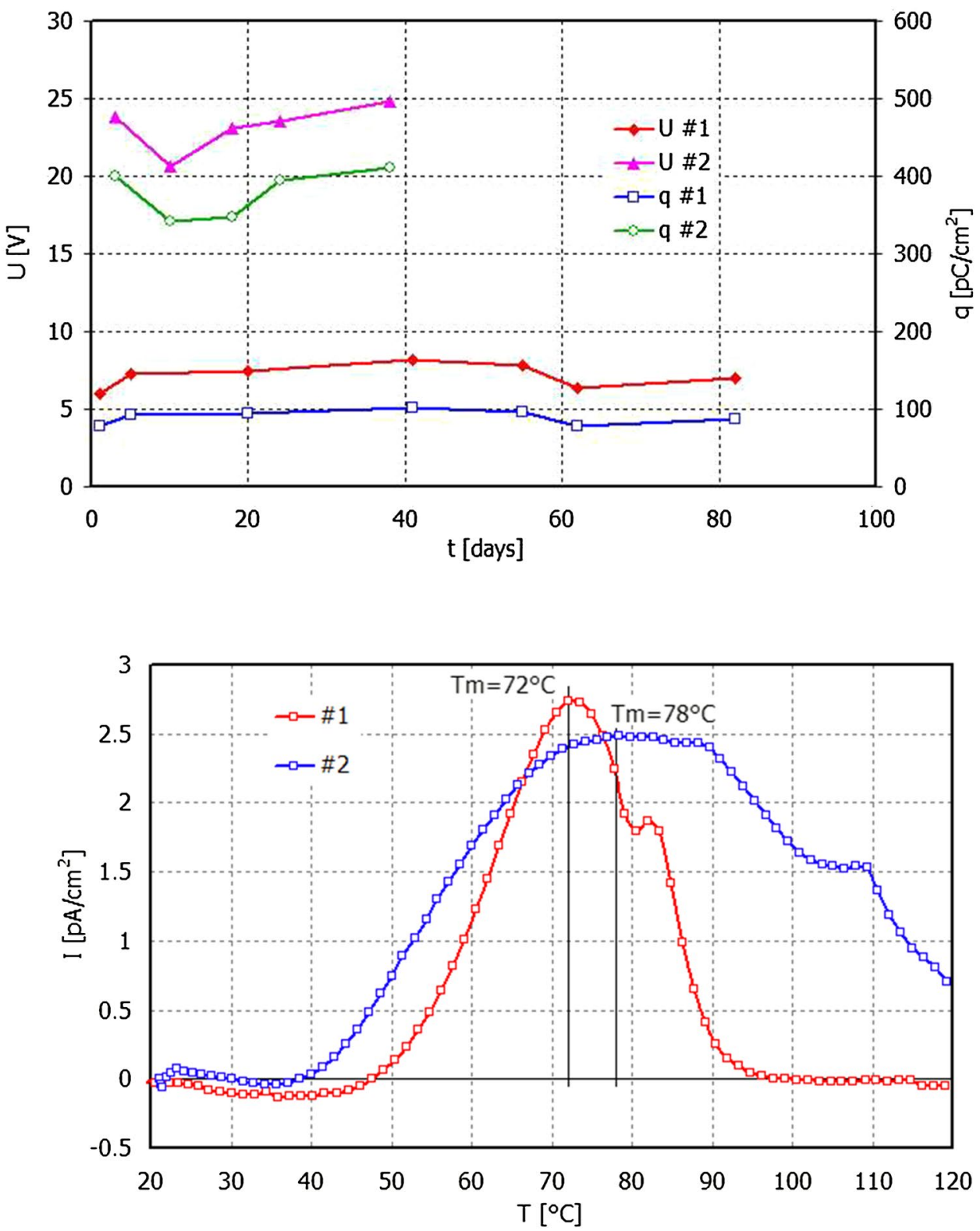

respectively. The upper limit of temperature range TR was set to $25 \%$ of peak height (Figs. 7,8 ).

Since function $\ln (\mathrm{I}(\mathrm{T}))$ over that range is not linear in practice, and therefore the computation of the slope is not unique, it was decided to modify the initial-rise method algorithm. The modification bases on determining a set of tangent lines with corresponding slopes and calculating their weighted average. The procedure for obtaining the weights was as follows. Using least squares method a trend lines were fitting to 3,4 , etc. points from the start point TL until a match over the whole temperature range (to a temperature TR) was reached. The standard error (SE) and the correlation coefficient $\left(\mathrm{R}^{2}\right)$ was calculated for each line giving the weight $\left(\mathrm{R}^{2}\right)^{\wedge} 2 / \mathrm{SE}$. The relationship between weighted slope and calculated activation energy is described by the Eq. (2). The Figs. 7 and 8 show initial-rise method plot with tangent line corresponding to calculated activation energy for electrets made of extruded and compacted films attains 2.67 and $3.28 \mathrm{eV}$, respectively.

Piezoelectric constant $d_{33}$ was calculated from dependence piezoelectric charge density versus stress what was shown in Fig. 9. As we can see from this the piezoelectric constant values were $\sim 18 \mathrm{pC} / \mathrm{N}$ and $\sim 75 \mathrm{pC} / \mathrm{N}$ for extruded and compacted film, respectively at low stresses and diminishes twice within higher stresses. The test made for comparative purposes for piezoelectric PVDF film attained values from 16 to $50 \mathrm{pC} / \mathrm{N}$, which is consistent with the literature data [31]. The compacting process of foamed PE advantageously influences the piezoelectric properties and durability of electrets. 
Fig. 7 Dependence of $\ln I$ as a function of $1 / \mathrm{T}$ and the fitting straight line for electrets made of extruded film

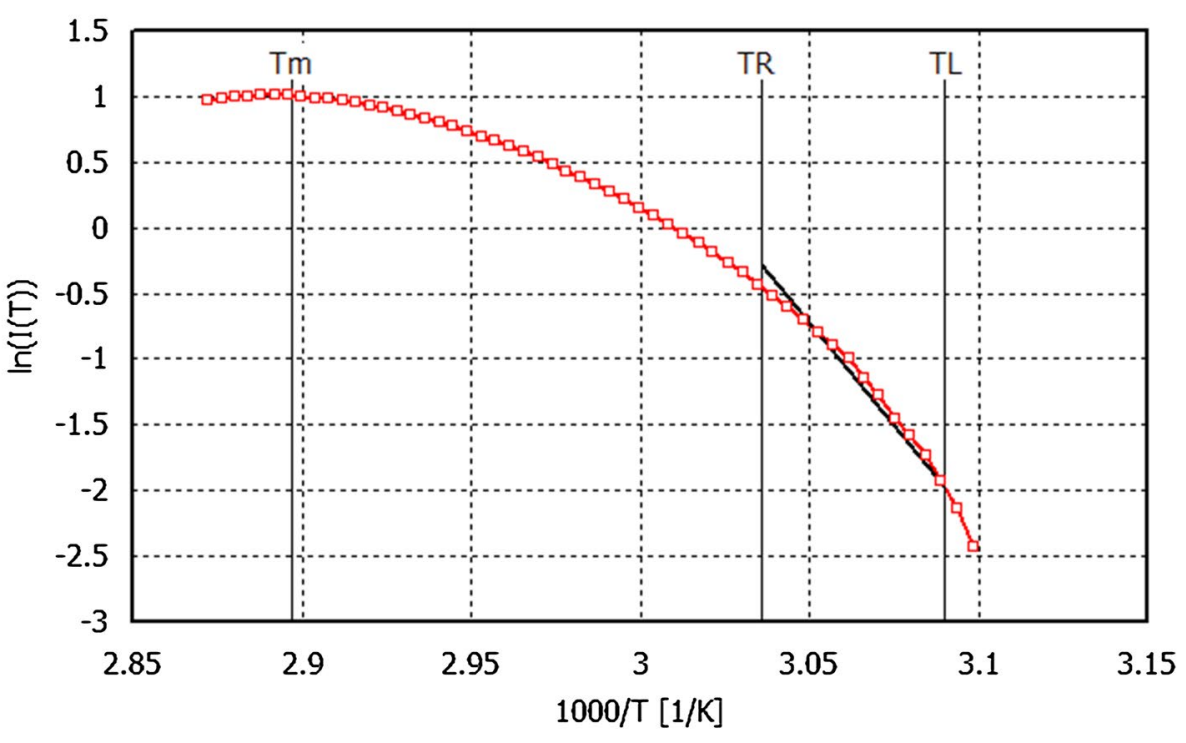

Fig. 8 Dependence of $\ln I$ as a function of $1 / \mathrm{T}$ and the fitting straight line for electrets made of film compacted at $140^{\circ} \mathrm{C}$

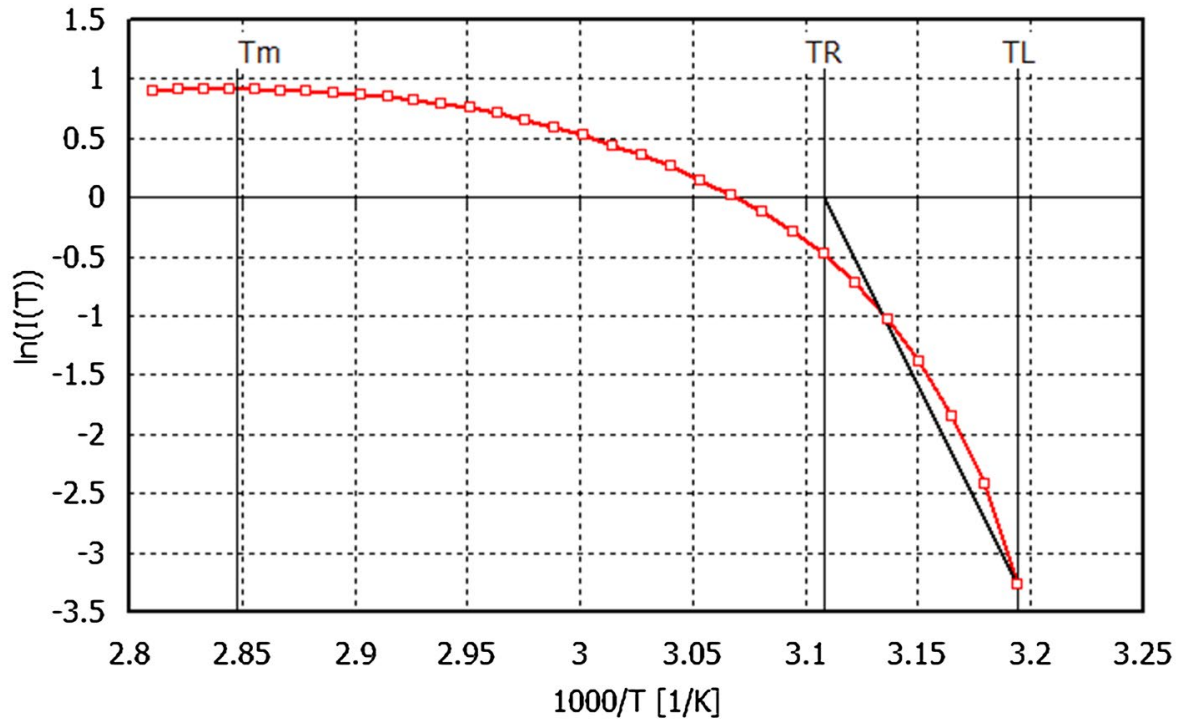

\section{Conclusions}

Physicochemical properties of foamed MDPE has been characterized by few instrumental methods. XRD allowed to determine the degree of crystallinity and monitoring changes in arrangement of the macromolecules in the samples subjected to processing. FTIR/Raman spectroscopy showed the purity of polyethylene studied. SEM revealed internal and surface morphology. The presence of voids in polymer film enabled the creation of electrets under the electric field of constant intensity. Piezoelectric effect in cellular MDPE depends on film heat treatment and structure as well as on temperature of polarization. The durability of this system is satisfactory.

The research showed that film compacting process positively influences the growth of the crystallinity of the tested material as well as its mechanical strength and considerable growth of the piezoelectric constant $d_{33}$.

It can be concluded that foamed PE films can be used for manufacturing valuable, piezoelectric materials which opens perspectives for production new low-cost sensors or strain gauges for biomedical application.

Thanks to these favorable properties, the discussed modified MDPE is the subject of a patent application (no. P.422119 from July 4th, 2017). 
Fig. 9 Dependence of charge density and piezoelectric constant $d_{33}$ versus stress

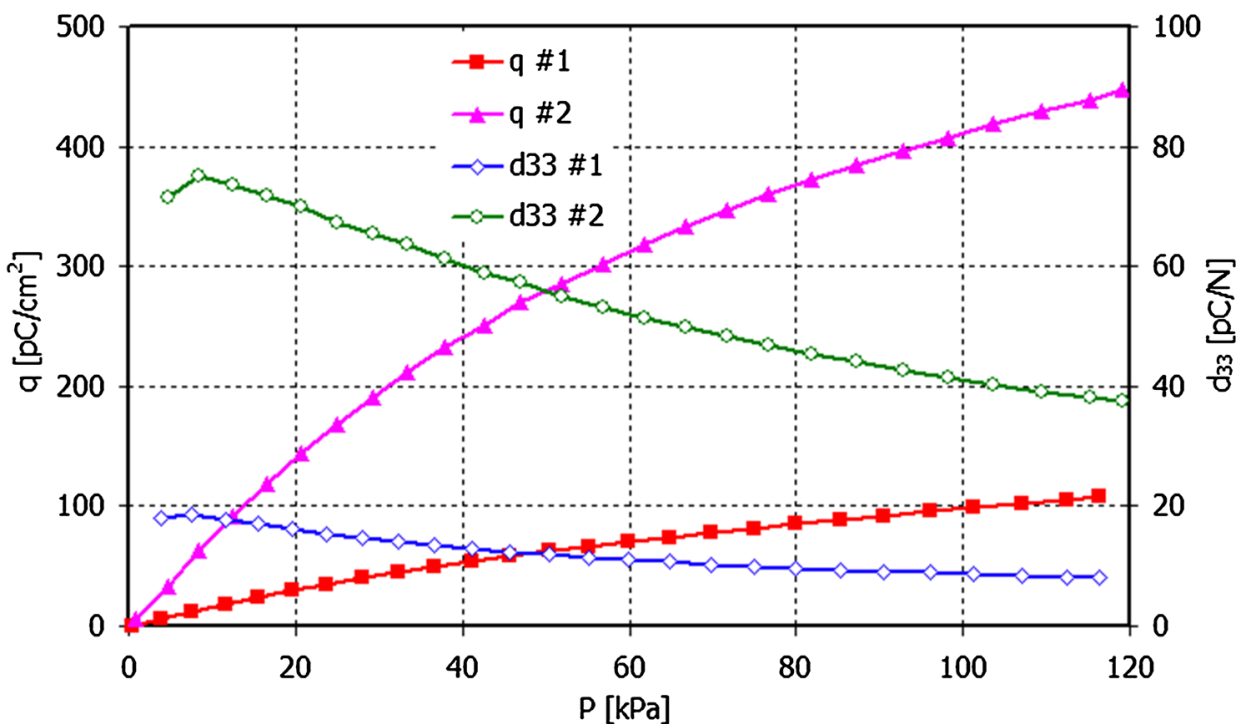

Acknowledgements This research was supported by National Science Centre, Poland (Grant No. 2015/17/B/ST8/03396). The authors thank Mr Andrzej Cichocki (ITE, Kraków) for the measurements of piezoelectric properties.

Open Access This article is distributed under the terms of the Creative Commons Attribution 4.0 International License (http:// creativecommons.org/licenses/by/4.0/), which permits unrestricted use, distribution, and reproduction in any medium, provided you give appropriate credit to the original author(s) and the source, provide a link to the Creative Commons license, and indicate if changes were made.

\section{References}

1. P.S. Chum, K.W. Swogger, Prog. Polym. Sci. 33, 797-819 (2008)

2. M. Stürzel, S. Mihan, R. Müllhaupt, Chem. Rev. 116, 1398-1433 (2016)

3. N.M.G. Franssen, J.N.H. Reek, B. de Bruin, Chem. Soc. Rev. 42, 5809-5832 (2013)

4. G. Rojas, E.B. Berda, K.B. Wagener, Polymer 40, 2985-2995 (2008)

5. M.D. Schultz, N.F. Sauty, K.B. Wagener, Appl. Petrochem. Res. 5, 3-8 (2015)

6. J. Hopewell, E.R. Dvorak, Kosior. Philos. Trans. R Soc. Lond. B Biol. Sci. 364(1526), 2115-2126 (2009)

7. L.S. Boffa, B.M. Nowak, Chem. Rev. 100, 1479-1493 (2000)

8. T.C. Chung, Functionalisation of Polyolefins (Academic Press, London, 2002)

9. P. Ciselli, L. Lu, J.C.J. Busfield, T. Peijs, e-Polymers 14, 1-13 (2010)

10. Y. Yang, H. Zhang, X. Zhong, F. Yi, R. Yu, Y. Zhang, Z.L. Wang, ACS Appl. Mater. Interfaces 6, 3680-3688 (2014)

11. K.T. Chong, X. Su, E.J.D. Lee, S.J. O'Shea, Langmuir 18, 9932 $9936(2002)$

12. A. Mellinger, F.C. Gonzalez, R. Gerhard-Multhaupt, Appl. Phys. Lett. 82, 254-256 (2003)

13. X. Zhang, G.M. Sessler, J. Hillenbrand, J. Electrostat. 65, 94-100 (2007)

14. M. Tang, Z. An, Z. Xia, X. Zhang, J. Electrostat. 5, 203-208 (2007)

15. E. Klimiec, B. Królikowski, M. Machnik, W. Zaraska, J. Dzwonkowski, J. Electron. Mater. 44, 2283-2291 (2015)
16. H. Kaczmarek, B. Królikowski, E. Klimiec, J. Kowalonek, J. Mater. Sci. (2017). doi:10.1007/s10854-016-6329-9

17. A. Qaiss, H. Saidi, O. Fassi-Fehri, M. Bousmina, Polym. Eng. Sci. 52, 2637-2644 (2012)

18. Z. An, M. Mao, J. Cang, Y. Zhang, F. Zheng, J. Appl. Phys. 111, $024111(2012)$

19. H. Gilbert-Tremblay, F. Mighri, D. Rodrigue, J. Cell. Plast. 48, 341-354 (2012)

20. A. Mohebbi, F. Mighri, A. AJjji, D. Rodrigue, Adv. Polym. Tech (2016). doi:10.1002/adv.21686

21. T. Krause, Rozkład ładunków swobodnych i wolnorelaksacyjnej polaryzacji w materiałach aktywnych (Distribution of free charges and slow relaxation polarization in active materials), Doctoral Thesis, Wroclaw University of Technology, (Wrocław, 2006) pp. 57-61

22. M. Psarski, E. Piotrowska, A. Galeski, Macromolecules 33, 916$932(2000)$

23. W. Li, H. Yang, M. Shang, T. Chen, W. Wang, Ind. End. Chem. Res. 55, 8719-8725 (2016)

24. K. Tomaszewska, J. Kałużna-Czaplińska, W. Jóźwiak, Polimery 55, 222-226 (2010)

25. S. Kumar, R.K. Singh, J. Pet. Eng. 987568, 1-7 (2013). doi:10.1155/2013/987568

26. S.A. Deshmukh, G. Kamath, V.G. Pol, S.K.R.S. Sankaranarayanan, J. Phys. Chem. 118, 9706-9714 (2014)

27. T. Furukawa, H. Sato, Y. Kita, K. Matsukawa, H. Yamaguchi, S. Ochiai, H.W. Siesler, Y. Ozaki, Polym. J. 38, 1127-1136 (2006)

28. Technical data sheet: Borealis Borcell ${ }^{\mathrm{TM}}$ ME1244 Medium Density Polyethylene http://www.matweb.com/search/datasheettext.aspx?m atguid=a1b2fa83c9d248a49716946999a31db9 (Accessed 10 April 2017)

29. N.S. Rawat, M.S. Kulkarni, D.R. Mishra, B.C. Bhatt, C.M. Sunta, S.K. Gupta, D.N. Sharma, Nucl. Instrum. Methods Phys. Res. B 267, 3475-3479 (2009)

30. T. Krause, Rozkład ładunków swobodnych i wolnorelaksacyjnej polaryzacji w materiałach aktywnych, Thesis, Wroclaw University of Technology, Wrocław, 2006, pp. 57-61 (in Polish)

31. Measurement Specialties Inc., Piezo Film Sensors Technical Manual. http://www.tufts.edu/programs/mma/emid/piezo.pdf (Accessed 17 July 2017) 